\title{
COMUNICACIÓN PERIODÍSTICA. NOTAS DESDE UNA PERSPECTIVA DE GÉNERO
}

JUAN-FRANCISCO TORREGROSA CARMONA

Universidad Rey Juan Carlos (Madrid)

\section{INTRODUCCIÓN: LA SITUACIÓN PRESENTE DEL PERIODISMO COMO PUNTO DE ARRANQUE}

La vieja idea de la construcción social de la realidad, motivo de honda preocupación para los sociólogos y politólogos más avezados, cobra en la época actual una nueva dimensión, un impulso nuevo debido a los medios de comunicación.

Sería un error pensar que hoy estamos ante un escenario totalmente novedoso. Pero no lo sería menos ignorar que hoy el periodismo, como forma concreta de comunicación de amplio alcance, se halla justamente en entredicho por múltiples motivos. Y siendo así, resulta de extraordinario interés estudiar de qué manera se relacionan la comunicación y los temas de género. Se trata de un espacio académico emergente por motivos obvios. Ya en los años noventa se consideraba que al tratar sobre el género se estaba ante un discurso social en auge ${ }^{1}$.

La dimensión más positiva de las aportaciones intelectuales y de lo ya conquistado en el terreno de la praxis es que indudablemente las mujeres, y con ellas buena parte de los hombres, no se conforman con un avance que, incluso espectacular en determinados aspectos, no alcanza los niveles suficientes de justicia social y dignidad.

Para poder conocer la situación de la mujer en el ámbito de la comunicación, en tanto que protagonista de informaciones periodísticas pero también como profesional de los medios, es necesario referirse al contexto de la transición que se vive hoy desde los viejos perfiles profesionales hasta las nuevas funciones (incluso desvirtuando los desempeños más tradicionales), con una hibridación clara propiciada fundamentalmente por el espectacular avance de las tecnolo-

1. GARCía DE LEÓN, María Antonia: Élites discriminadas (sobre el poder de las mujeres), Barcelona, Anthropos, 1994, p. 25. 
gías, particularmente Internet, en el escenario digital que va inexorablemente dejando atrás al mundo analógico.

La situación por la que atraviesa hoy el periodismo en el caso español, de manera similar bien es cierto a lo que ocurre en muchas otras latitudes comparables, es una situación en la que el espectáculo sigue ganando terreno a los dominios de la información, algo que influye en los espacios y en los tratamientos de los contenidos noticiosos. Un nuevo paradigma no sólo tecnológico sino, muy importante, también social. Eso es lo que representa hoy Internet. Por tanto, es mucho más amplio que un mero medio, aunque también lo sea. En realidad conforma toda una inmensa plataforma de comunicaciones, medios y servicios. La Red supera todas las fronteras geográficas y contribuye poderosamente a esa idea extendida de la globalización, sin bien no para todos, algo que no se debe olvidar. Se puede decir que estamos, para aquellos a los que alcanza la Red, ante la materialización de un sueño que ya nos contaron, aunque fuese intuyéndolo, escritores y novelistas de prodigiosa imaginación (Julio Verne, Borges...). Razón llevaba Shakespeare cuando aseguraba en La Tempestad que los seres humanos estamos hechos de la misma materia que los sueños. Para el escritor Juan José Millás, con el ciberespacio hemos inventado un espejo; la realidad virtual pasa a convertirse en una suerte de gran espejo de lo analógico.

Lo que Gabriel García Márquez considera el mejor oficio del mundo, en un artículo excelente que retrata muchos de los problemas por los que se atraviesa en la actualidad, tiene que adaptarse también a unos tiempos de mercantilismo exacerbado al que no escapan unos medios de comunicación que están pendientes más que nunca de los índices de audiencia, aunque se trate de contenidos informativos y de medios públicos. La evolución tecnológica, económica y social del periodismo y la comunicación en general en España ha sido espectacular. Hace tan sólo tres decenios, redacciones con pocos teléfonos, grandes, apenas unos cuantos ordenadores, "gigantes» a la vista actual, con una pantalla de un solo color, las fotos transmitidas a distancia por Telefax y aun sistemas más precarios. Hoy con Internet eso no es ya historia, sino prehistoria casi... Ya vamos por la fotografía digital, los bancos de imágenes de alta calidad alojados en la Red y tantas cosas más.

Viendo la evolución de la labor de los periodistas hasta llegar al momento actual, pareciera que han pasado no veinte o treinta sino cincuenta o setenta años, por la magnitud impresionante del cambio. La Red, como todo, presenta una doble cara. Ha revolucionado, literalmente, la información y su registro, la documentación, en todas sus vertientes: personal o privada, profesional, de investigación... pero lo que no cambia, antes al contrario, casi se diría que aumenta es la necesidad de cautela y verificación: hay que contrastar, evaluar....

La realidad es que no está todo en Internet, ni es información todo lo que se cuelga en la Red. Y no conforma, insistamos, un mero medio de comunicación: es una plataforma de medios y servicios, que implica algo muy distinto, de mucho más largo alcance. Convertida la Red en muchas ocasiones en el canal o el vehículo perfecto para difundir rumores, las viejas reglas del oficio, muchas de ellas no escritas, siguen siendo premisas ineludibles. Hoy es más 
acuciante que nunca la necesidad de formación y de autoformación que ha existido siempre. Porque con la formación se abren mayores y mejores posibilidades de conocimiento y de lucha contra la desinformación. O contra la excesiva presencia (o mejor, seguidismo brutal) de las fuentes de la comunicación empresarial e institucional, en el marco de un nuevo modelo: la búsqueda de información propia es cada vez más difícil: antes se buscaba desde la información del día a día hasta la de los grandes reportajes de investigación; hoy la noticia persigue al periodista y no al revés, lo que supone un cambio radical, abismal, ante el que cada vez más voces autorizadas claman por intentar una especie de vuelta a los orígenes, dentro de lo posible, para que sean los propios medios de comunicación los que controlen al menos algo la agenda mediática $y$ sus contenidos informativos.

A ello se une otro gran problema que discrimina en este caso por partida doble a las mujeres: la precariedad laboral de periodistas y colaboradores («si no firmo el comunicado, el refrito, no cobro", entre otros muchos aspectos). Es un fenómeno que se da en toda España. Para muestra un hecho: hace unos pocos años, más del ochenta por ciento de los periodistas en ejercicio eran menores de cuarenta años ${ }^{2}$. Cabe pensar que hoy, unos cuantos años después, se vive una situación similar o incluso más descarnada.

\subsection{Las mujeres como profesionales de la comunicación periodística española}

En una profesión con una no alta, altísima, presencia femenina, la realidad es que los trabajos de campo demuestran que todavía hoy el techo de cristal sigue existiendo para las mujeres dentro de los medios de comunicación ${ }^{3}$. Tanto para las que desempeñan su labor como periodistas como para aquellas otras que trabajan en las demás categorías laborales características de las empresas informativas, sean éstas de titularidad pública o de capital privado. Y no sólo por las especiales dificultades de acceso a los puestos directivos dentro de los periódicos y los medios audiovisuales y digitales, aunque constituya dicha dimensión una de las más conocidas o destacadas por quienes estudian estos temas, que advierten similares problemas en otros ámbitos como la política, la universidad o la empresa en general.

Existen diversos estudios sobre la situación de la mujer profesional del periodismo o del campo de la comunicación en general. Han sido realizados por el Instituto de la Mujer, por el Instituto Andaluz de la Mujer y por los de otras Comunidades Autónomas, por investigadores de la Universidad o por las Asociaciones de la Prensa.

2. Ortega, Félix y Humanes, María Luisa: Algo más que periodistas. Sociología de una profesión, Barcelona, Ariel, 2000.

3. NúÑEZ, Trinidad y LOSCERTALES, Felicidad: «Ser mujer y periodista en el siglo XXI: un deporte de riesgo", en M. Arriaga, J. Baca, C. Castaño y M. Montoya (eds.): Desde Andalucía: mujeres del Mediterráneo, Sevilla, Arcibel, 2006, pp. 354-365. 
Nosotros podemos hacer un sencillo ejercicio que sin embargo arroja resultados demoledores. Se trata de coger la Agenda Nacional de la Comunicación, o las autonómicas, del año en curso, o de años recientes, y no digamos si nos vamos más atrás en el tiempo, que editan la Presidencia del Gobierno, los gobiernos autonómicos y organismos institucionales o profesionales diversos, y contar el número de periódicos o de empresas de radio y televisión, o de gabinetes de prensa, que existen en todo el Estado o en la Comunidad determinada que estudiemos.

¿Cuántas de esas empresas de comunicación están dirigidas por una mujer? ¿Cuántas redactoras jefas hay, cuántas jefas de sección? ¿Cuáles son las proporciones, cuantitativas y cualitativas, de sus puestos respecto a los ocupados por los hombres?

La situación sólo es «normal», por así decirlo, en el caso de las corresponsales de los distintos medios y agencias en buena parte de las provincias españolas, donde la presencia de la mujer está acorde con su mayoritaria presencia en la profesión, pero estos puestos no son directivos, ni mucho menos, sino uno de los ámbitos en los que el problema generalizado de la precariedad de cientos de miles de trabajadores y trabajadoras es más elevado, tanto desde el punto de vista cuantitativo, por la gran cantidad de periodistas a los que afecta, como cualitativo, por la gravedad y la duración en el tiempo de las situaciones en las que han de sobrevivir los colaboradores y otros empleados sin contrato laboral escrito o permanente.

Desde la consideración de la radiografía en el ámbito nacional, hasta hace pocos años había dos directoras de periódico: uno regional en Murcia y un diario económico de difusión nacional, pero que no es de los de mayor audiencia. Lo peor es que pasan los años y la situación aunque mejora -por ejemplo hay algunas directoras de periódico más, pero muy pocas, entre decenas y decenas de cabeceras- no lo hace en la suficiente medida, de tal modo que sigue siendo apreciable la mayor dificultad para desempeñar una labor profesional dentro de la comunicación para las mujeres, transcurridos más de treinta años desde que empezaron a licenciarse las primeras promociones de periodistas tituladas mediante el nuevo sistema de formación superior. La mayoría de esos egresados eran mujeres y hoy la proporción es de mayores dimensiones.

En el caso de Andalucía, la situación es algo más alentadora en el caso de la empresa pública RTVA: tras el director general, hay una directora del Canal 2 Andalucía, una directora de Canal Sur Televisión, unas cuatro directoras territoriales, etcétera. Pero la mejora de la situación se remonta a los cambios decididos y realizados por el director general hace pocos años, en un organismo autonómico de radiotelevisión que existe desde 1989 y que nunca ha contado con una directora general. En el caso de RTVE, desde su nacimiento en los años cincuenta del pasado siglo, sólo ha tenido a lo largo de tanto tiempo dos directoras generales: la cineasta Pilar Miró y, más recientemente, la catedrática Carmen Caffarel.

La situación de la mujer en los medios sigue, por tanto, acusando problemas comunes a los de los hombres (alta precariedad, significativa incidencia del in- 
trusismo profesional, acoso moral o psicológico: el denominado «mobbing»...) y específicos (difícil acceso a puestos de responsabilidad o de dirección, acoso sexual en ocasiones, graves dificultades para conciliar la vida familiar y la profesional, en especial respecto al embarazo y la maternidad...).

El panorama presente de la mujer y de todos aquellos quienes hoy trabajan dedicados a las diversas facetas del periodismo está mejorando algo por la acción de los Sindicatos de Periodistas, de reciente creación, cuya labor no obstante choca con grandes fuerzas en el seno de las empresas informativas que moderan, y a veces incluso frustran, sus logros tanto profesionales como específicamente laborales.

En los puestos de responsabilidad de las Asociaciones de la Prensa, agrupadas en la FAPE, y de los concretos sindicatos territoriales de la Federación Española de Sindicatos de Periodistas (FESP), hay presencia de mujeres, como no podía ser de otra manera, siendo tantas en la profesión. Ahora bien, tampoco están en la primera línea de dirección, por lo general. A modo de muestra, destaquemos que de las ocho provincias andaluzas, desde la Transición a la Democracia hasta hoy, sólo una o dos han ido contando con una mujer como presidenta de la asociación de periodistas, si bien en casi todos los casos ha habido una mujer como secretaria o secretaria general, es decir, en el siguiente lugar del organigrama. La situación hoy es perfectamente equiparable a ese panorama de nuestra historia reciente descrito a modo de síntesis evolutiva.

La presencia física de la mujer en los medios como profesional es tan alta que si la situación no cambia de forma considerable a medio plazo habrá que considerar que la gravedad respecto a la llegada a puestos directivos está basada en un modelo que no confía en las mujeres, que no les hace justicia y que sigue patrones de conducta machista o retrógrada, se sea consciente o no de ello.

Donde la situación de la mujer periodista es mejor, tanto en presencia de primera línea como en calidad del empleo, es en la comunicación institucional y corporativa (gabinetes de Prensa, direcciones de Comunicación e Imagen, departamentos de Relaciones Externas, etcétera). En estos puestos que existen en empresas, instituciones, organismos, universidades, hay muchas mujeres trabajando desde hace años, y cada vez más la profesión cuenta con Jefas de Prensa y Directoras de Comunicación, lo cual sin duda entraña una mejora para todos.

Es verdad que en ocasiones existen ofrecimientos a la mujer para que asuma un puesto de responsabilidad y declina hacerlo. Pero no es creíble que se deba, tan sólo y ni siquiera de forma principal, a la suma de voluntades individuales de las periodistas una situación que es claramente "anómala» y que da que pensar respecto a la existencia o no de una igualdad real, estructural, entre hombres y mujeres, más allá de los avances puntuales o "formales», por nombrarlo de alguna manera. $\mathrm{Y}$ al margen, por consiguiente, de la igualdad legislativa o jurídica que tiene hoy España pero que no logra traspasar lo suficiente las fronteras de lo parlamentariamente aprobado para garantizar a nivel fáctico el cumplimiento 
de lo que esas mismas disposiciones y normas del ordenamiento jurídico establecen con carácter vinculante, de manera obligatoria.

En el ámbito de lo jurídico que referimos es de destacar la reciente Ley de Igualdad (Ley Orgánica 3/2007 para la Igualdad efectiva entre mujeres y hombres), que en relación con los medios de comunicación establece, en el Título III, diversas medidas de fomento de la igualdad al estipular que los medios de comunicación social de titularidad pública deberán velar por una transmisión igualitaria, plural y no estereotipada de las mujeres, así como colaborar en campañas institucionales dirigidas al fomento de la igualdad y a erradicar la violencia de género. Del mismo modo, los medios de titularidad privada deberán respetar la igualdad y elaborar códigos de autorregulación. Esta norma incluye una disposición que estimamos de especial relevancia: la publicidad discriminatoria se entenderá ilícita.

Para transformar las leyes en hechos cotidianos y generalizados, el reto verdadero es que mujeres y hombres, hombres y mujeres, seamos capaces de tener la suficiente inteligencia y la lucidez necesaria para saber que esta realidad nos afecta a todos y que sin el concurso de todos no se avanzará todo lo que hace falta ni todo lo rápido que es preciso. No olvidemos que la igualdad entre sexos, como la igualdad de oportunidades para los ciudadanos al margen de su situación económica, de su discapacidad o de otros factores, es algo que está intrínsecamente unido al respeto o ultraje de la dignidad de las personas $y$, por tanto, de los derechos humanos.

En este contexto, ante este déficit, es grato saber que contamos con el valioso legado y las acciones ejemplares de pensadoras y de pioneras como Concepción Arenal, Carmen de Burgos (Colombine), María Zambrano, entre muchas otras, (del ámbito internacional: Hannah Arendt, Betty Friedan, Simone de Beauvoir, Simone Weil, Mary Douglas, etcétera) que nos pueden servir como magnífica guía para iluminar nuestros pasos en unos tiempos que son siempre de cambio, y que de todos depende que sean de cambio para mejor, es decir, de avance y no de perpetuación en la asimetría o incluso de retroceso.

Por eso, la apuesta política por la paridad entraña valentía y decisión, y el tiempo dirá cuáles han sido los resultados de fondo. Parece estar claro que la dificultad hoy se halla más en el mundo de la empresa privada, periodística o no, y en otros ámbitos, que en la política o las instituciones públicas, esferas en las que, pese a todo, subsisten problemas y prejuicios, como el hecho de prestar una distinta atención y ofrecer un diferente tratamiento informativo a las esferas públicas y privadas de las mujeres y de los hombres que cuentan con una dedicación a la política activa.

\section{EL TRATAMIENTO DE LA MUJER EN LOS MEDIOS INFORMATIVOS GENERALISTAS. DE LO REAL A LO IDEAL}

Los resultados obtenidos por recientes estudios empíricos nos permiten afirman que el tratamiento que ofrecen los medios de comunicación sobre las mujeres dista, en ocasiones mucho, de ser el mismo que el que aportan sobre 
los hombres, en este caso respecto a las personas que están dedicadas a la política ${ }^{4}$.

La representación mediática de la mujer, de lo que tiene que ver con ella, está atravesada muchas veces por tópicos, simplificaciones e incluso agresiones más o menos notorias. Y eso tanto en la información como, sobre todo, en la publicidad. Es una realidad compartida con los tratamientos similares dados a minorías, sectores con dificultades particulares, etcétera. Una realidad propia de una sociedad del espectáculo y la frivolidad, base del éxito social y económico de los productos y los procesos mediáticos.

En los tiempos actuales probablemente conviven las más burdas imágenes publicitarias o injusticias informativas respecto a la mujer con nuevos y más sutiles modos de marginación y estigmatización. Los anuncios televisivos son buena muestra de una forma de presentar y representar a las mujeres que no difieren, en la esencia, aunque sí en los artificios y los modos narrativos, de las concepciones más rancias y estereotipadas, cuya extensión hasta el resto de la población masculina no conlleva sino agravar el problema en términos sociales.

Los nuevos códigos deontológicos de los que hace poco tiempo se han dotado las televisiones públicas y privadas a instancias del Gobierno de España suponen un soplo de esperanza respecto a las posibilidades, siempre limitadas pero absolutamente necesarias de cambio. No podemos olvidar que lo que podría denominarse como "los límites de lo tolerable» y de lo fácticamente tolerado en el campo de la comunicación pública colectiva no han parado de aumentar en los últimos años, últimos pero muchos, siempre demasiados...

Ya en 1995 la IV Conferencia Mundial sobre las Mujeres celebrada en Pekín dictó una serie de medidas que deberían adoptar gobiernos, medios de comunicación, agencias publicitarias y otros organismos y agentes públicos y privados con el fin de alcanzar dos objetivos primordiales. El primer objetivo estratégico consistía en aumentar el grado de participación y de acceso de las mujeres a los espacios de toma de decisiones, de debate y de exposición de ideas de los medios y, a través de ellos, a las nuevas tecnologías de la información. Por su parte, el segundo objetivo estratégico pasaba por fomentar una imagen de las mujeres equilibrada y sin estereotipos en los medios.

Efectivamente, además del aspecto cualitativo (tratamiento) hay que preocuparse también por la dimensión meramente cuantitativa (presencia), habida cuenta de que diversos estudios han constatado que las mujeres son entrevista-

4. Una de esas investigaciones es la titulada «La representación de la mujer en los medios de comunicación: comparación entre los contenidos y las percepciones de la mujer». Investigadores principales: Antonio García Jiménez y Gloria Gómez-Escalonilla. Equipo de investigación: Marina Santín, Raquel Rodríguez y Juan Francisco Torregrosa (Universidad Rey Juan Carlos). Proyecto financiado por la Dirección General de la Mujer de la Comunidad de Madrid y realizado durante el año 2006 (inédito).

5. AZnAR, Hugo: Ética de la comunicación y nuevos retos sociales. Códigos y recomendaciones para los medios, Barcelona, Paidós, 2005, pp. 243-267. 
das y mencionadas en los espacios informativos de las radios y las televisiones españolas en una proporción sensiblemente menor que la de los hombres.

Este hecho difícilmente podría responder sólo a causas que se pudieran encontrar únicamente en los propios medios, sino también a aspectos estructurales, más de fondo, inherentes a la propia sociedad, que sigue sin confiar y dar oportunidades a todos en una medida idéntica o cuando menos similar. Por ejemplo, en los equipos de gobierno se sigue contando con las mujeres para áreas como Educación, Cultura o Medio Ambiente; pero difícilmente, mucho menos, aunque también, para las carteras de Interior, Economía o Asuntos Exteriores.

Junto a lo anterior, la evaluación aun somera de la prensa especializada femenina, desde sus orígenes hasta la actualidad de las principales y conocidas revistas (Cosmopolitan, Vogue, Telva, Mía, Marie Claire, AR y más de una docena de cabeceras aparte que alcanzan una audiencia de hasta medio millón de personas para muchas de ellas) nos ofrece un continuo tratado de tópicos, prototipos, arquetipos y estereotipos desde los de naturaleza sexual de más grueso calado hasta los que encubren unos tintes menos descarados pero igualmente nocivos y contrarios a cualquier camino de igualdad y enfoque ecuánime hacia las propias mujeres en sí mismas consideradas pero también respecto a su relación con los hombres, e incluso con el entorno y la sociedad coetánea en general. Otro tanto ocurre en bastantes casos con publicaciones mensuales específicamente dirigidas a los hombres y por supuesto en todos los ejemplos de la conocida como prensa rosa o del corazón 6 .

Aunque no podemos ocuparnos de él por razones de espacio y de acotación temática, es particularmente cotidiano y grave el caso de la publicidad y sus evidencias de discriminación de género, empleando todo tipo de métodos con el fin de acaparar la atención y lograr los objetivos comerciales y de notoriedad de marca perseguidos con campañas que a veces denigran a la mujer, y en puntuales ocasiones también al hombre, hasta no respetar en más de un caso extremo aspectos mínimos de dignidad humana.

Por fortuna, la sociedad cuenta hoy con observatorios de la publicidad no sexista y con instituciones públicas fuertes que les ofrecen respaldo para denunciar tales atropellos intentando evitar males mayores que los que consiguen ocasionar cuando se ponen de acuerdo una empresa y una agencia publicitaria con pocos o nulos escrúpulos.

\subsection{Ante el drama de la violencia contra las mujeres}

En las noticias sobre violencia de género vemos, aunque menos que hace unos años, tratamientos informativos que presentan muchas carencias y que

6. Para conocer los orígenes y la actualidad de la llamada prensa femenina, recomendamos acudir a sendos trabajos rigurosos y documentados: el libro de Adolfo PERINAT y María Isabel MARRADES: Mujer, prensa y sociedad en España. 1800-1939, Madrid, CIS, 1980 y el artículo de Juana GALLEGO AYALA: "La prensa femenina: una cala de difícil abordaje», en J. J. Fernández (coord.): Prensa especializada actual. Doce calas, Madrid, McGraw-Hill, 2008, pp. 131-175. 
dejan traslucir equívocos largamente mantenidos de forma más o menos consciente. Cuántas veces echamos de menos que esas informaciones cumplan, si no todas, sí al menos la mayoría de las características que habría de tener una Noticia diez, según el código elaborado por la ya mencionada Federación de Asociaciones de la Prensa de España (FAPE) bajo del título de Noticias con lazo blanco:

1. «Situar la violencia doméstica en el marco de los derechos humanos.

2. Evitar presentar la noticia desconectada de otras similares.

3. No caer en estereotipos, prejuicios y tópicos.

4. Investigar también lo que no se ve.

5. Distinguir claramente entre víctima y agresor.

6. Crear opinión e influir en la sociedad.

7. No recrearse en el amarillismo.

8. Intentar reflejar la complejidad de la realidad.

9. No conformarse sólo con las fuentes informativas policiales.

10. Dar también información útil y complementaria».

Este último punto resulta fundamental, de ahí que debamos considerar un avance el compromiso de las televisiones y otros medios informativos de asumir como rutina profesional la inclusión en sus piezas periodísticas de rótulos y menciones al teléfono gratuito 016 de atención y ayuda a las víctimas de la violencia de género.

Dicha recomendación también está en la iniciativa más reciente llevada a cabo en 2008 por los propios medios de comunicación. En este caso, el diario Público ha elaborado un código autorregulatorio, un decálogo para informar sobre la violencia de género (como el propio periódico explica, aunque el Diccionario de la Lengua de la Real Academia Española (RAE) no acepta oficialmente, por el momento, la expresión violencia de género, sí lo hace en la edición de su Diccionario Panhispánico de Dudas, publicado en octubre de 2005).

Por su parte, el Diccionario de Español Urgente, editado por la prestigiosa Agencia EFE, afirma que el término género se emplea para «describir el distinto comportamiento de hombres y mujeres en la sociedad según las distintas condiciones en que se mueven: educación, familia, cultura, etcétera».

Merece la pena conocer de qué manera pretende el citado diario encarar la violencia machista desde el tratamiento ofrecido por las informaciones que cada día elaboren sus profesionales:

1. "Usaremos los términos "violencia de género», "violencia machista», "violencia sexista» y "violencia masculina contra las mujeres», por este orden. Rechazamos las expresiones «violencia doméstica», "violencia de pareja» y "violencia familiar».

2. La violencia de género no es un suceso, sino un problema social. Por ello, no le daremos ese tratamiento. No publicaremos fotos ni detalles morbosos.

7. "Noticias con lazo blanco. Manual para periodistas sobre la violencia doméstica», Unió de Periodistes Valencians. Edición de la Federación de Asociaciones de la Prensa de España (FAPE), 2002. 
3. Nunca identificaremos a las víctimas ni incluiremos información que pueda perjudicarlas a ellas o a su entorno.

4. Respetaremos siempre la presunción de inocencia de los agresores. Una vez haya sentencia condenatoria, los identificaremos debidamente, destacaremos el castigo e intentaremos incluirlo en los titulares.

5. Nunca buscaremos justificaciones o «motivos» (alcohol, drogas, discusiones...). La causa de la violencia de género es el control y el dominio que determinados hombres ejercen contra sus compañeras.

6. Evitaremos las opiniones de vecinos o familiares que no hayan sido testigos directos de los hechos. En cualquier caso, nunca recogeremos opiniones positivas sobre el agresor o la pareja.

7. Intentaremos ofrecer opiniones de personas expertas en la materia. Priorizaremos las opiniones policiales y de la investigación. No se informará con precipitación.

8. Sólo incluiremos testimonios de víctimas de malos tratos cuando no se hallen en situación de emergencia o bajo cualquier tipo de presión.

9. Denunciaremos también la llamada violencia continuada (agresiones, maltrato psicológico... aunque no tenga resultado de muerte).

10. Siempre incluiremos en la noticia el teléfono gratuito de ayuda a las víctimas (016) y cualquier otra información que les pueda ser útil»8.

La estricta observancia de estas normas éticas podría llegar a impedir graves hechos como el asesinato que acabaría con la vida de la ciudadana rusa afincada en España Svetlana, "cuyo apellido -como bien critica Ramón Irigoyen- es omitido generalmente por los diarios porque ya se sabe que a las mujeres basta con nombrarlas con el nombre de pila", tras su paso por el espacio televisivo $E l$ diario de Patricia. Uno de los problemas es que "Antena 3, como otras cadenas, manipula a los entrevistados ocultándoles la información de las personas con las que van a encontrarse en el programa ${ }^{9}$.

\section{HACIA UNA ÉTICA DE LA COMUNICACIÓN DE LOS PROBLEMAS SOCIALES}

Es necesario que se logre alcanzar una ética de la alteridad especialmente en lo que afecta a todos los temas relativos a problemas sociales y culturales de los que a diario necesitan dar cuenta a toda la ciudadanía los medios informativos.

Porque la consideración continua de lo deontológicamente aceptable, de lo cuestionable y de lo directamente rechazable es inherente a la práctica fundacional del periodismo y las actividades análogas, por mucho que los cuantiosos y graves ejemplos que podemos encontrar en sentido contrario parecieran desmentir tal afirmación.

A lograr ese objetivo, difícil y necesario, pueden y deben contribuir normas de autocontrol como las que ya hemos visto en este trabajo, pero necesariamen-

8. «Decálogo para informar sobre la violencia de género", Diario Público, 20 de enero de 2008, p. 28.

Disponible en http://www.publico.es/espana/039045/manual/redactor

9. IRIGOYEN, Ramón: «Asesinatos de mujeres», El País (sección Madrid, 24/11/2007). 
te se tendrá que contar con instituciones externas con capacidad sancionadora real, en la línea de los consejos audiovisuales (sigue pendiente desde hace demasiados años la creación de uno de ámbito nacional) y organismos similares, así como con el concurso de otras instancias.

Entre ellas, juzgamos esencial el papel que corresponde desempeñar a la escuela y al resto de instituciones características de los procesos formales de enseñanza y aprendizaje.

\subsection{La mujer y la palabra pública: el imprescindible concurso de la educación formal y el valor de las primeras periodistas}

La alianza estratégica entre los campos de la Comunicación y la Educación ofrece unas extraordinarias potencialidades que no se puede dejar de aprovechar. Como muy bien saben los grupos que actúan en esta línea, el trabajo con los medios en la escuela supone un magnífico campo para educar en la diversidad, en los valores más necesarios para la convivencia democrática... y todo ello a partir del conocimiento de lo que ha sido considerado el gran hilo conductor de la historia: los medios de comunicaciones y sus representaciones.

Cada vez está más claro que esa afirmación está llena de sentido. Hoy todas las realidades, para ser tales en términos sociales, han de estar presentes en los medios informativos, con la evidente característica de que en función de cómo, cuánto, por quiénes, etcétera, representadas estén, así serán en buena medida en la calle, en la propia realidad.

Como planteábamos al principio de este texto, la conocida teoría de la construcción social de la realidad tiene hoy la fuerza y la vigencia que le da la construcción mediática de la realidad. A partir de las ideas expuestas, en especial desde esta última consideración, adquieren gran valor las siguientes palabras escritas por la que fue consejera de Educación de la Junta de Andalucía, Cándida Martínez, elaboradas cuando era Decana de la Facultad de Filosofía y Letras de la Universidad de Granada:

«Podemos afirmar que en la sociedad actual pervive, aunque en diferentes grados, según la zona, una configuración del mundo creada hace bastantes siglos que atribuye papeles sociales diferentes a mujeres y a hombres, que implica una relación de desigualdad y de poder. Mientras que el colectivo masculino ha sido definido como portador del «logos», de la creatividad, de la palabra pública, del poder, las mujeres aparecen ligadas a la naturaleza, mediatizadas por su propia biología, recluidas en el silencio, socializadas en el «no poder». Esta relación de desigualdad de géneros ha sido considerada como natural, y por tanto argumentada y justificada a lo largo del tiempo por filósofos, políticos, científicos y por la religión. Y cada sociedad ha generado mitos y ritos encargados de reproducir esta relación de género» ${ }^{10}$.

10. MARTíneZ, Cándida: «El silencio y la palabra. Reflexiones desde la historia de las mujeres», Actas del curso Educación en valores y temas transversales del currículum, Sevilla, Junta de Andalucía, 1997, pp. 101-114. 
La verdad de estas afirmaciones se comprueba en el inteligente interrogatorio que somete a valoración pública la escritora mexicana Ángeles Mastretta en su obra Puerto libre. La cita es necesariamente larga pero sin ninguna duda merece la pena conocerse:

«Sin ánimo de volver a hacernos las mártires, debemos aceptar cuánto pesa buscarse un destino distinto al que se previó para nosotras, litigar, ahora ya ni siquiera frontalmente, dado que los movimientos de liberación femenina han sido aplacados porque se considera que sus demandas ya fueron satisfechas, con una sociedad que todavía no sabe asumir sin hostilidad y rencores a quienes cambian. Me preguntaba hace poco un periodista: ¿¿Por qué a pesar de todo lo logrado, las mujeres hacen sentir que no han logrado la igualdad? ¿Qué falta? Falta justamente la igualdad, le respondí. ¿Por qué si un hombre tiene un romance extraconyugal es un afortunado y una mujer en la misma circunstancia es una piruja [en México, prostituta]? ¿El hombre un ser generoso al que la da el corazón para dos fiebres y la mujer una cualquiera que no respeta a su marido? ¿Por qué no nos parece aberrante un hombre de cincuenta años entre las piernas de una adolescente y nos disgusta y repele la idea de una mujer de treinta y cinco con un muchacho de veintiséis? ¿Por qué una mujer de cuarenta y cinco empieza a envejecer y un hombre de cuarenta y cinco está en la edad más interesante de su vida? ¿Por qué detrás de todo gran hombre hay una gran mujer y detrás de una gran mujer casi siempre hay un vacío provocado por el horror de los hombres a que los vean menos? ¿Por qué los esposos de las mujeres jefes de Estado no se hacen cargo de las instituciones dedicadas al cuidado de los niños? ¿Por qué a nadie se le ocurre pedirle al esposo de una funcionaria de alto nivel que se adscriba al voluntariado social? ¿Por qué las mujeres que ni se pintan ni usan zapatos de tacón son consideradas por las propias mujeres como unas viejas fodongas cuando todos los hombres andan en zapatos bajos y de cara lavada sintiéndose muy guapos? ¿Por qué se consideran cualidades masculinas la fuerza y la razón y cualidades femeninas la belleza y la intuición? :Por qué si un hombre puede embarazar a tres distintas mujeres por semana y una mujer sólo puede embarazarse una vez cada diez meses, los anticonceptivos están orientados en su mayoría hacia las mujeres? Y puedo seguir: ¿Por qué al hacerse de una profesión las mujeres tienen que actuar como hombres para tener éxito? ¿Por qué los pretextos femeninos -tengo la regla o mi hijo está enfermo- no pueden ser usados para fallas en el trabajo, y los pretextos masculinos -estoy crudo, perdonen ustedes pero vengo de un tibio lecho, por ejemplo- son siempre aceptados con afecto y complicidad? ${ }^{11}$

La autora todavía realiza unas cuantas observaciones relevantes más que por razones de espacio no podemos reproducir ahora. En todo caso, si tenemos alguna respuesta para estas preguntas, habremos de convenir que hemos de ser ante todo ciudadanos, antes que hombres y mujeres, y por tanto sujetos iguales en derechos y obligaciones. Así lo reclamaba Clara Campoamor en su discurso a favor del voto de las mujeres durante las Cortes constituyentes de la República el 1 de octubre de 1931: «Yo, señores diputados, me siento ciudadana antes

11. MastretTA, Ángeles: Puerto libre, Madrid, El País-Aguilar, 1994, pp. 138-140. 
que mujer, y considero que sería un profundo error político dejar a la mujer al margen de ese derecho.... ${ }^{12}$.

Para finalizar esta parte de la exposición, nos gustaría retomar brevemente la evocación de la figura de la escritora y periodista de prestigio internacional citada al principio de este trabajo: Carmen de Burgos Seguí (Almería, 1867 - Madrid, 1932), que firmaba sus trabajos periodísticos sobremanera con el pseudónimo de Colombine. Considerada ya en su tiempo la primera mujer española en ejercer el periodismo, fue ella la primera corresponsal de guerra del país, como enviada especial a Melilla en la guerra de África de 1909, y absoluta pionera en tantas otras cosas, entre ellas su incansable labor como luchadora a favor de la igualdad entre mujeres y hombres, lo que según cuentan sus biógrafos le valió todo tipo de insultos y furibundos ataques personales por parte de los sectores más retrógrados y reaccionarios de los difíciles días que le tocó vivir y contar como articulista (hoy diríamos columnista) y como reportera a pie de calle.

Sin ninguna duda su compromiso vital la llevó a estar a la vanguardia del feminismo, entendido éste como esfuerzo sin tregua para avanzar en la igualdad de género, de especial valor por estar en tiempos duros, incluso oscuros, cuando era muy poca gente (con un altísimo precio a pagar) la que se atrevía siquiera a sugerir o a plantear la más mínima subversión del orden «natural» de las cosas entre mujeres y hombres. A la biografía de Carmen de Burgos le hacen justicia aquellas palabras de la célebre cita de Jacqueline L. Tobin: «Las historias fueron silenciadas. Las vidas, olvidadas. Ahora el silencio se rompe; un corazón se eleva. Las mujeres hablan».

Recordando el legado de Colombine, y al tratar sobre comunicación y género, sobre mujer y medios de comunicación, es preciso realizar una propuesta genérica, en el mismo sentido de hablar o callar, que engloba muchas otras. Se trata, como ha escrito la profesora Cándida Martínez, de «educar, especialmente a las chicas, en la utilización de la palabra pública, como herramienta de comunicación, de reflexión, de cultura, como instrumento primario y primero para entrar en el mundo de los iguales» ${ }^{13}$.

\section{CONCLUSIONES}

Sería injusto y poco realista negar que el tratamiento periodístico que los distintos medios ofrecen sobre la mujer es la mayoría de las veces correcto y equiparable, en todo caso, al que ofrecen sobre los hombres. Ahora bien, no es menos cierto que sigue habiendo una discriminación simbólica que deja de lado, aunque no siempre, tratamientos más burdos. Sin embargo, deben denunciarse tanto las realidades más descarnadas como aquellas otras mucho más numerosas en las que el tratamiento deontológicamente inaceptable también se da, pese a la necesidad de agudizar o entrenar un poco más la mirada.

12. CAMPOAMOR, Clara: Mi pecado mortal. El voto femenino y yo, Sevilla, Instituto Andaluz de la Mujer, Junta de Andalucía, 2001.

13. MARTíneZ, Cándida: Op. cit., p. 114. 
Se podría establecer un cierto símil que vendría a demostrar que la ausencia de lo peor no implica estar en el mejor de los mundos posibles. Ni tan siquiera en uno aceptable. Esa comparación consistiría en pararse a pensar que a la censura brutal, particularmente grosera y lacerante de los cuarenta años de dictadura del franquismo la han sustituido hoy formas mucho más sutiles pero muy efectivas: por ejemplo, la situación de «indignidad» laboral en la que están muchos profesionales de la comunicación. De hecho, a veces hay medios informativos, en todos los ámbitos geográficos, también en España, que no nacen como proyectos editoriales, periodísticos, sino como proyectos políticos, de partido, de lobby o grupo de presión, constructores, por ejemplo.

El tratamiento periodístico, y especialmente el publicitario, desequilibrado que sufre la mujer no es sino una de las dos caras de la misma moneda de la injusticia. La otra cara es la mayor dificultad de ascenso y normal desempeño profesional en el campo de los medios de comunicación. Uno de los aspectos más visibles es la escasez de mujeres que ocupen los primeros niveles directivos en periódicos y emisoras de radio y televisión. Algo mejor es la situación por lo que respecta a la comunicación empresarial e institucional (direcciones de comunicación y jefaturas de prensa).

En todo caso las discriminaciones más o menos sutiles persisten tanto en los tiempos y espacios dedicados a la mujer por los medios como en su forma cualitativa de concreción, así como en las diferencias que presentan las características y los obstáculos que se deben salvar en las carreras profesionales de mujeres y de hombres en el sector de la comunicación.

\section{BIBLIOGRAFÍA}

ArriagA, Mercedes; BaCA, Jesús; CASTAÑo, Clara y Montoya, María (eds.): Desde Andalucía: mujeres del Mediterráneo, Sevilla, Arcibel editores, 2006.

AZNAR, Hugo: Ética de la comunicación y nuevos retos sociales. Códigos y recomendaciones para los medios, Barcelona, Paidós, 2005.

BocK, Gisela: La mujer en la historia de Europa, Barcelona, Crítica, 2001.

CAMPOAMOR, Clara: Mi pecado mortal. El voto femenino y yo, Sevilla, Instituto Andaluz de la Mujer - Junta de Andalucía, 2001.

CorreA, Ramón I.; GuZMÁn, María Dolores; AguAded, J. Ignacio: La mujer invisible. Una lectura disidente de los mensajes publicitarios, Huelva, Grupo Comunicar ediciones, 2000.

GarCÍA-AlBI, Inés: Nosotras que contamos. Mujeres periodistas en España, Barcelona, Plaza y Janés, 2007.

Gallego AyAlA, Juana: "La prensa femenina: una cala de difícil abordaje», en J. J. Fernández (coord.): Prensa especializada actual. Doce calas, Madrid, McGraw-Hill, 2008, pp. 131-175.

GARCÍA DE LEÓN, María Antonia: Élites discriminadas (sobre el poder de las mujeres), Barcelona, Anthropos, 1994.

INSTITUTO ANDALUZ DE LA MUJER: Medios de comunicación y violencia contra las mujeres, Sevilla, 2003.

INSTITUTO OFICIAL DE RTVE: Representación de la violencia de género en los informativos de TVE: conclusiones, Madrid, 2005.

INSTITUTO NAVARRO DE LA MUJER: Mujer publicada, mujer mal tratada, Pamplona, 2003. 
IRIGARAY, Luce: Yo, tú, nosotras, Madrid, Cátedra, 1992.

IRIGOYEN, Ramón: «Asesinatos de mujeres», El País (sección Madrid, 24/11/2007).

LAFUente, Isaías: Agrupémonos todas. La lucha de las españolas por la igualdad, Madrid, Punto de Lectura - Santillana, 2003.

LOREnTE ACOSTA, Miguel: Mi marido me pega lo normal. Agresión a la mujer: realidades y mitos, Barcelona, Ares y Mares - Crítica, 2001.

MARTÍNEZ, Cándida: "El silencio y la palabra. Reflexiones desde la historia de las mujeres». Actas del curso Educación en valores y temas transversales del currículum, Almería, Junta de Andalucía, 1997, pp. 101-114.

MastretTA, Ángeles: Puerto libre, Madrid, El País-Aguilar, 1994.

NúNEEZ, Trinidad y LOSCERTALES, Felicidad: "Ser mujer y periodista en el siglo XXI: un deporte de riesgo", en M. Arriaga, J. Baca, C. Castaño y M. Montoya (eds.): Desde Andalucía: mujeres del Mediterráneo, Sevilla, Arcibel, 2006, pp. 354-365.

ORTEGA, Félix y Humanes, María Luisa: Algo más que periodistas. Sociología de una profesión, Barcelona, Ariel, 2000.

PlaZA, Juan F. y DelGADO, Carmen (eds.): Género y comunicación, Madrid, Fundamentos, 2007.

Perinat, Adolfo y MARRADES, María Isabel: Mujer, prensa y sociedad en España. 18001939, Madrid, CIS, 1980.

Utrera, Federico: Memorias de Colombine. La primera periodista, Madrid, Hijos de MuleyRubio, 1998.

VAlCÁRCEL, Amelia y Romero, Rosalía (eds.): Pensadoras del siglo XX, Sevilla, Instituto Andaluz de la Mujer, 2001.

Fecha de recepción: 26-02-2008

Fecha de aceptación: 07-03-2008 